\title{
Online and Offline Hybrid Teaching in the Luminescent Materials and Applications Course
}

\author{
Jie Li1*, Yali Yao², Qiang Guo' \\ ${ }^{1}$ College of Optoelectronic Engineering, Chengdu University of Information Technology, Chengdu 610225, Sichuan \\ Province, China \\ ${ }^{2}$ School of Physical Education, Chengdu Normal University, Chengdu 611130, Sichuan Province, China \\ *Corresponding author: Jie Li, lijie@cuit.edu.cn \begin{abstract}
out online teaching in completing their teaching tasks. After the epidemic, the online and offline hybrid teaching has become a novel mode of teaching which meets the requirements of teaching reform and the information society. This teaching method integrates both the online and offline teaching which plays an important role in enhancing teaching qualities and learning experiences. However, due to the lack of experience, there are some issues occurring in the teaching process of this method. The Luminescent Materials and Applications course is used as the subject in this article. The difficulties in traditional offline teaching as well as the advantages, detailed course construction process, and effectiveness evaluation of hybrid teaching are summarized and meticulously analyzed. In regard to that, the application of the online and offline hybrid teaching in the Luminescent Materials and Applications course is beneficial to the learning of professional knowledge and the cultivation of students' scientific literacy. Therefore, it is an effective way to improve and enrich this course by using the online and offline hybrid teaching method.
\end{abstract} \\ Abstract: Due to the outbreak of COVID-19, colleges and universities have actively responded to the call of the state to carry
}

Keywords: Online teaching; Offline teaching; Hybrid teaching; Luminescent materials and applications

Publication date: June 2021; Online publication: June 30, 2021

\section{Introduction}

Luminescent Materials and Applications course is a professional course for undergraduate students of applied physics. This course predominantly includes classification, application, performance evaluation, and research progress of inorganic luminescent materials, rare earth luminescent materials, organic luminescent materials and devices. This course enriches students' professional knowledge, establish scientific research methods, as well as cultivate scientific literacy and engineering design abilities. However, the traditional teaching method in this course emphasizes on spoon-feeding which neglects students' learning autonomy, flexibility, and creativity. ${ }^{[1]}$ Therefore, in order to improve the teaching quality of the Luminescent Materials and Applications course, more effective teaching methods should be introduced to promote students' initiative, participation before, during, and after classes, as well as improve their abilities to analyze and solve problems. In view of the sudden outbreak of COVID-19 in 2020, online education has become increasingly important in China especially under their Ministry of Education requirements to suspend classes without stopping learning. After the epidemic, the hybrid teaching method has become significantly important in the teaching reform of their colleges and universities. ${ }^{[2-6]}$ Hence, it has been selected as a new method to be introduced into the Luminescent Materials and Applications course. The advantages, detailed course construction process, and effectiveness evaluation of this hybrid teaching as well as the issues in traditional offline teaching are summarized and systematically analyzed. 


\section{Difficulties in traditional offline teaching}

The theoretical teaching of Luminescent Materials and Applications in many colleges and universities have adopted the traditional teaching method of classroom teaching in large classes and is supplemented by afterclass tutoring. This teaching method often causes problems. First, in terms of teaching contents, traditional teaching mainly emphasizes the systematicness and integrity of the curriculum knowledge system but neglects professionalism which results in students' failure to understand the practical application value of the course and creates incongruity between the teaching of "general knowledge" and "professional needs." Second, in terms of teaching modes, it stresses the imperative teaching in large classes while neglecting students' independent exploratory learning. Eventually, students passively accept knowledge, rarely participate in class, and the teacher-student interaction is lacking. Third, in terms of teaching evaluations, the focus is on mid-term and final term assessments. The evaluation of students' learning process is also neglected in this case which causes a difficulty in determining students' abilities in learning and problemsolving. These three problems of the traditional teaching method restrict the teaching effect of the course in order to cultivate innovative talents.

\section{Advantages of online and offline hybrid teaching}

During the spring semester in 2020, China's Ministry of Education issued the suspension of classes without stopping learning. The online teaching effectively solved restrictions in regard to time and space. Teachers have been able to evaluate students' learning outcomes from multiple dimensions. Through online teaching, students' participation in classes and other aspects have improved. With computers and modern internet technologies, teachers could select and upload relevant teaching resources to teaching platforms while students have been able to gain knowledge in a suitable manner according to their own learning styles. With the rapid development of teaching platforms and teaching resources, the online and offline hybrid teaching method has been widely used and analyzed. ${ }^{[7-11]}$

For courses with a large number of practical applications such as Luminescent Materials and Applications, it is difficult to draw students' attention using traditional teaching methods but in combination with video-based online teaching methods, it is more attractive. An example of a combination of offline teaching (left) of luminescence principle and video-based online teaching (right) is shown in Figure 1. The mechanism of luminescence is complicated hence, it is difficult to understand based on a single picture in the offline teaching method. However, it becomes incredibly interesting and charming if a video is selected to display the subject. The advantages of online and offline hybrid teaching have sparked the interest of administrative departments in colleges and universities. In addition to that, some of them have tried to enhance the hybrid teaching to achieve more remarkable results.
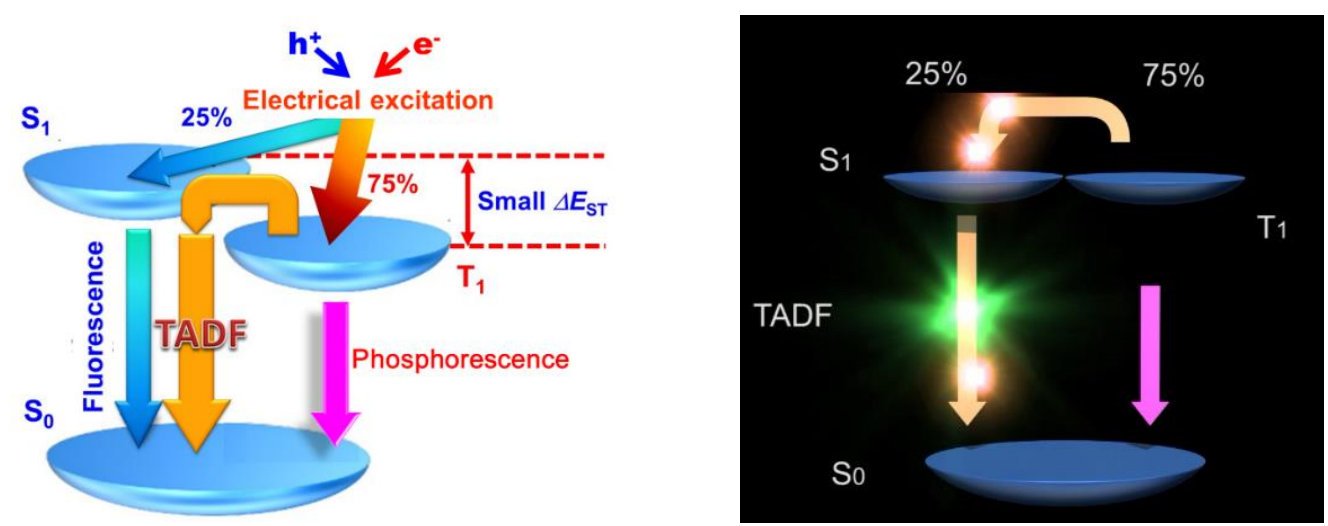

Figure 1. Example of the combination of offline teaching (left) of luminescence principle and corresponding video-based online teaching (right) 


\section{Construction of online and offline hybrid teaching}

\subsection{Teaching objective}

The online and offline hybrid teaching in the Luminescent Materials and Applications course combines teaching contents with students' majors, subject frontiers, and personalized learning to create a first-class "golden course."

In this way, it actively develops and excavates high-quality course resources, complements each other in the online and offline hybrid teaching, improves course quality and innovates course forms, stimulates students' initiative and creativity in independent learning, embodies the student-centered teaching concept, as well as improves the quality of undergraduate talent cultivation. The hybrid teaching arrangements for the Luminescent Materials and Applications course are depicted in Table 1.

Table 1. Online and offline hybrid teaching arrangements for the Luminescent Materials and Applications course

\begin{tabular}{llrc}
\hline \multicolumn{1}{c}{ Chapter } & \multicolumn{1}{c}{ Main content } & Class hours & Teaching method \\
\hline \multirow{2}{*}{ 1. Introduction } & Luminescence and classification of luminescent materials & 2 & Offline teaching \\
& Performance evaluation and application of luminescent materials & 2 & Offline teaching \\
\hline 2. Inorganic & Luminescent principle and classification & 2 & Offline teaching \\
luminescence & Preparation and application & Luminescent principle and classification & Online teaching \\
\hline 3. Organic & Preparation and application & 4 & Offline teaching \\
luminescence & Luminescent principle and classification & 4 & Online teaching \\
\hline 4. Rare earth & Preparation and application & 2 & Offline teaching \\
luminescence & Research progress & 4 & Online teaching \\
\hline 5. Outlook of & Opportunities and challenges & 4 & Offline teaching \\
luminescent materials & & 4 & Online teaching \\
\hline
\end{tabular}

\subsection{Construction steps}

First, it is necessary to construct online platforms in which the Massive Open Online Courses (MOOCs) and Tencent conference are examples. The former provides abundant teaching resources while the latter is convenient for communication between teachers and students. Second, the course is refined into relatively independent and complete knowledge points according to the teaching syllabus and other requirements which are in line with high-quality online teaching resources. Third, questions that are raised during the learning process are timely answered which is beneficial to emphasize key points, help students to further grasp systematic knowledge, understand the inherent logic of the knowledge unit, integrate knowledge unit into a complete system, create perfect knowledge frameworks, and enrich the details within the framework of knowledge nodes. Fourth, the gradual integration of teaching ideas and methods in lessons based on all kinds of information trainings and observation classes are vital. All these can promote the improvement of teachers' informatization teaching ability.

\subsection{Course construction}

The Luminescent Materials and Applications course uses two textbooks in which one of it is Luminescence Principle and Luminescent Materials which is edited by Qi Kangcheng and Cao Guichuan and published by the University of Electronic Science and Technology of China Press. The other is Rare Earth Luminescent Materials: Fundamentals and Applications which is edited by Hong Guangyan and published 
by Science Press. The five chapters which are included in this course are introduction, inorganic luminescence, organic luminescence, rare earth luminescence, and prospect of luminescent materials. Each chapter includes principles, classifications, preparations, and applications. In order to provoke the learners' interests, teaching methods such as problem-oriented learning, expository method, teamwork, and materials object-demonstrations are used.

\subsection{Online teaching resources construction}

According to the requirements of the teaching syllabus and based on the academic calendar, all knowledge points of the course are divided into relatively independent and complete parts in line with high-quality online resources. Teachers would upload learning materials and teaching plans of the course in advance onto the online teaching platforms for students to download and preview prior classes. This provides more time for students to put together clear key points and issues raised in the learning contents. In addition to that, teachers would provide course-related seminar questions and guide the students with those questions while stimulating their enthusiasm for learning as well as improving their skills in finding, solving, and putting forward problems. All in all, on the one hand, online platform resources are used to provide abundant resources for students in facilitating them to enrich their knowledge and widen their perspectives while on the other hand, it also supports in the preparation for offline lessons.

\subsection{Offline course construction}

The key in constructing offline courses lies in the course contents and the improvement of teachers' informatization teaching ability. With the online teaching, students would have a preliminary understanding of knowledge points. Therefore, the main duty of teachers in classrooms is to answer students' questions, highlight difficult issues, help students to have a deeper understanding of knowledge in a systematic way, grasp the inherent logic of knowledge unit, integrate the branch of unit knowledge into a complete system, as well as enrich details within the framework of knowledge nodes. Offline teaching would try to transform the roles of teachers and students, enrich the classroom assessment evaluation system, guide students to learn and think together, and fully reflect the main status of students in classrooms. All these would comprehensively promote students' interest in learning and lay the foundation to achieve efficient classroom virtuous circle.

\subsection{Application of online and offline hybrid teaching}

In the application of hybrid teaching, teachers would select high-quality course resources, use PowerPoints, electronic textbooks, and other learning materials in the online teaching platforms in order to continuously cultivate students' ability to learn independently. Offline classroom emphasizes on the combination of explanations as well as question and answer-based interactions. Besides, teachers would explain the key and difficult issues in the online learning process to guide students in their independent learning while supplementing them by answering questions and solving their doubts.

The teaching design of the online and offline hybrid course is designed based on three aspects which are the teaching stage, teaching activities, and the development of students' learning activities. In the teaching stage, the design of the course content is mainly displayed. First of all, teachers would upload learning tasks on the learning platforms prior classes and students would complete the corresponding tasks on these platforms while conducting Q\&A discussions. Teachers would also modify their teaching strategies according to the students' learning levels before lessons. Then, classroom teaching activities are designed to help students improve their skills from perceptual cognition to internalization of knowledge, master the key contents, and achieve a breakthrough of difficult issues in the learning process. 


\subsection{Teaching feedback mechanism}

The online and offline hybrid teaching emphasizes on strengthening process assessment and process evaluation system to improve teaching qualities while traditional evaluation methods emphasize on students' final examination results. The process assessment of the hybrid teaching concerns more about the students' learning process while process evaluation covers the whole teaching process which would enhance students' subjective initiative and improve teaching qualities. Evaluation of teachers toward students as well as the supervising experts and students toward teachers are included and emphasized in the hybrid teaching method. Teachers would then conform to the trends over time, learn to use the data provided by teaching platforms, as well as to record students' pre-class independent learnings, participation in classes, and extended learning after-class. The online platforms are used to check students' learning reports, keep up with students' class attendance and activity participation, as well as understand students' learning attitudes and interests accurately. This information provides evidence for teachers to improve their teaching methods and modify teaching contents to fit students' learning abilities.

For backward students, teachers would try to help and supervise them by referring to teaching records. Students who show strong interest in certain aspects would be guided to explore deeply and realize personalized learning. In addition, summaries and detailed data of students' access to resources, sign-ins, and participation in activities would also be exported. In hybrid teaching, weighted calculations are used as the basis in the process assessment of students. Relying on online teaching supervision mechanism, the flexible changes in teaching methods based on the opinions offered by supervising experts are possible. Moreover, evaluations and feedbacks from students would also promote modifications of teaching plans, improvement of teaching methods, and perfecting teaching designs over time.

\subsection{Effectiveness of online and offline hybrid teaching}

According to the design and development of online teaching resources and the requirements of teaching syllabus, the course knowledge is refined and broken down into relatively independent and complete knowledge points which are in line with high-quality online resources. Offline teaching focuses on key contents as well as difficult teaching contents while trying to solve problems that cannot be solved in the online teaching platform. By completing corresponding tasks, students are able to progress from perceptual cognition to knowledge internalization; hence, improving their skills and achieve breakthroughs with challenging contents. The application of online and offline hybrid teaching in courses should be carried out from three aspects which are the teachers' teaching activities, students' learning activities, and the evaluation of learning in order to create a process-based assessment and evaluation system for the improvement of teaching qualities and in the creation of first-class courses.

\section{Conclusion}

The online and offline hybrid teaching method is of great importance in the teaching reform of colleges and universities. In this context, this mode of teaching has been chosen as a new method to study its effect on the Luminescent Materials and Applications course. The difficulties in traditional offline teaching, as well as the advantages, detailed course construction process, and effectiveness evaluation of the online and offline hybrid teaching are carefully analyzed. Overall, the application of online and offline hybrid teaching in the Luminescent Materials and Applications course is beneficial to the learning of professional knowledge and the cultivation of students' scientific literacy. 


\section{Funding}

This work was supported by the 2019-2021 Undergraduate Teaching Project of Chengdu University of Information Technology (BKJX2020022, BKJX2020081) and Department of Human Resources and Social Security of Sichuan Province (2019Z226).

\section{Disclosure statement}

The author declares no conflict of interest.

\section{Author contributions}

Li J. conceived and supervised the whole study. Yao Y. contributed to the analysis and manuscript preparation, and Guo Q. provided lots of constructive suggestions.

\section{References}

[1] Yeh DD, Park YS, 2015, Improving learning efficiency of factual knowledge in medical education. Journal of Surgical Education, 72(5): 882-889.

[2] Wang Q, Huang C, Hu X, et al., 2021, The application of the online and offline interactive teaching method in clinical anesthesiology teaching. Education Research International, :1-6.

[3] Shang Y, Zhong Y, Chen Z, 2021, Exploration of online and offline mixed classroom teaching practice based on the flow theory. Education Study, 3(1): 45-49.

[4] Zhang N, Duan X, 2021, Integration of off-line \& on-line: the concept and action choice of online teaching of vocational education in post-epidemic era. Journal of Contemporary Educational Research, 5(4): 1-6.

[5] Hua S, Ren Z, 2020, "Online + offline" course teaching based on case teaching method: a case study of entrepreneurship education course. International Journal of Emerging Technologies in Learning, 15(10): 69-85.

[6] Zhou F, Duan Z, 2020, Practical exploration of the blended teaching of online and offline teaching for digital media art majors - taking flash graphic animation design as an example. Advances in Social Sciences, 09(09): 1365-9.

[7] Wang Q, Zhang H, Wang M, 202, Discussion on online and offline mixed teaching mode based on flipped classroom teaching. Creative Education Studies, 08(05): 792-6.

[8] Ge S, Jian Z, Xia Z, 2021, Innovative research on the blending learning mode of econometrics. Journal of Contemporary Educational Research, 5(4): 41-3.

[9] Liu Z, Wang F, Jiang F, et al., 2020, Research on teaching mode of "advanced manufacturing technology" based on the online and offline mixed module for the future. Creative Education Studies, 08(05): 787-91.

[10] Bao W, Research on the mixed teaching model in colleges and universities in the context of internet + . Asian Agricultural Research, 12(7): 71-4.

[11] Zhao S, 2021, Thinking of calculus teaching under two modes of online and offline. Advances in Social Sciences, 10(03): 538-41. 